\title{
Profitability Change in the Global Airline Industry
}

Davide Scotti: University of Bergamo, Department of Management, Information and Production Engineering, via Pasubio 7, 24044 Dalmine, BG, Italy.

Nicola Volta: Cranfield University, Centre of Air Transport Management, University Way, Cranfield, Bedfordshire MK43 0TR, UK.

Accepted version

\begin{abstract}
This paper studies airline profitability change computed through a Bayesian estimation of a cost function. The stochastic frontier is applied to a dataset including the largest worldwide airlines in the period 1983-2010. We show that productivity change is mainly driven by technical change becoming continuously positive from early 1990s. Furthermore, in the last decade profitability change is mainly driven by input price changes which exhibit a similar pattern to output price change. In presence of productivity growth, the output price increase is lower than the input price increase suggesting that part of productivity gains are transferred from airlines to consumers.
\end{abstract}

Airline; profitability, cost function, decomposition, efficiency 


\section{Please cite as:}

\section{Scotti, D., Volta, N. (2017). Profitability Change in the Global Airline Industry. Transportation Research Part E, 102, 1-12.}

\section{1) Introduction}

Airline profitability was not a main concern at the dawn of commercial aviation when state-owned carriers used to be supported by government subsidies and seats and fares were set according to inter-governmental agreements (the Economist, 2014). This led to weak incentives for cost reduction at the industry level until air transport liberalization waves (1980s in United States, early 1990s in Europe) dramatically changed airlines' condition, fostering (i) privatisations, (ii) competition and (iii) new business models. This new scenario, coupled with both a low countervailing power in the air transport vertical channel (Button, 2005 and Button and McDougall, 2006) and a structural vulnerability to outside shocks (Scotti and Volta, 2015), determined poor airline financial performances - despite their exponential growth in terms of traffic volumes (Brugnoli et al., 2015) - bringing to prominence the issue of airline profitability. As a result, several contributions focused on different issues such as (i) the relationship between profit fluctuations and industry value generation (IATA report, 2013), (ii) the cyclical dynamics of airline earnings (e.g. Hansman and Jiang, 2005 and Pierson and Sterman, 2013), (iii) the link between profitability and business models (e.g. Lawton, 2002; Franke and John, 2011) and (iv) the implication of different operations management practices (e.g. Barnhart et al., 2009).

Nevertheless, since the 1980s the transportation economics literature on airline performance focuses mainly on technical efficiency and total factor productivity (for a comprehensive review see $\mathrm{Yu}, 2016$ ). Studies have traditionally sought to establish how technical efficiency and productivity have changed over time and which factors have mainly driven such changes (Good et al., 1995 and Oum and Yu 1995). Other studies investigate airline cost efficiency (Oum and Zhang, 1991 and Oum and Yu, 1998) or both productivity and cost competitiveness (Oum and Yu, 2012 and Windle 1991;). ${ }^{1}$ However, looking only at efficiency and productivity tells only part of the story. This is confirmed also by (i) Windle and Dresner (1992) who show that total factor productivity is a poor proxy for profitability, (ii) Oum and Yu (1995) who state that airline productive efficiency alone does not lead necessarily to the success, and (iii) Heshmati and Kim (2016) who point out that the general lack of profitability among airlines is not always due to poor performance alone.

Our intent is to fill the gap in the literature regarding airline performance by computing airline profitability at the industry level and identifying the drivers of its change. Indeed, apart from efficiency and productivity, changes in profitability may be also related to other causes such as input price reduction and output price increase (i.e. airlines' mark-up increase). Hence, studying industry profitability and its decomposition may provide further significant information, especially from the regulatory point of view. On one hand, it may indicate whether airlines improving their performance are passing such gains to passengers. On the other hand, a complete knowledge of recent historic trends in industry profitability may reveal the most appropriate policy targets. As an example, if airlines are by now close to the efficient

\footnotetext{
${ }^{1}$ For a substantial review of the literature regarding cost functions in transportation industries see Oum and Waters (1996).
} 


\section{Please cite as:}

\section{Scotti, D., Volta, N. (2017). Profitability Change in the Global Airline Industry. Transportation Research Part E, 102, 1-12.}

frontier it may be time to shift the incentive schemes towards technological improvements or input prices reduction. Analysing a group of 53 world's major airlines in the period 1983-2010, the aim of this paper is to compute and untangle airline productivity and profitability quantifying the contribution of its different components. In order to do so, we adopt a cost function approach according to the following steps: (i) we estimate a stochastic cost function, (ii) we compute total factor productivity and its components, and (iii) we compute profitability and its components. A further merit of our paper is mainly methodological. Indeed we impose regularity conditions in a Bayesian estimation framework contrasting with the majority of the existing studies, which check the proportion of times the conditions are violated (Kumbhakar, 2015). In this work, the cost function regularity conditions are locally imposed following Terrell (1996).

\section{2) Methodology \\ 2.1 Cost function}

As pointed out by Chua et al. (2005) the empirical estimation of airline cost functions has a long and recognized tradition in the literature (e.g. Oum and $\mathrm{Yu}, 1998$, Oum and Zhang, 1991, Kumbhakar, 1992, etc.). Hence, according to previous contributions, we specify a technology where each airline minimizes the production cost given outputs and input prices. Since capital input is not always in equilibrium in the industry (Caves et al., 1984 and Gillen et al., 1990), we estimate a short-run cost function relaxing the assumption of optimal capital stock treating the capital as a quasi-fixed input. The general short-run cost function becomes as follows:

$$
V C=f(Y, \vec{W}, K, \vec{Z})
$$

where, $Y$ is the output, $W$ a vector of input prices, $K$ the quasi-fixed capital input and $Z$ a set of characteristic variables describing the heterogeneous nature of the airline networks (average stage length and number of destinations served). Due to its flexibility, the function form $(f)$ we apply is a translog so that the model is a secondorder approximation to any general cost function. Finally, the short-run cost function is estimated under a stochastic frontier framework, thus allowing deviation from the cost minimization objectives due to process inefficiencies. Different studies support the idea of airlines operating above the cost minimizing curve. Kumbhakar (1992) and Bitzan et al. (2014) show that airlines, acting as shadow cost minimizers, fail to meet the condition of actual cost minimization due to the existence of allocative distortion - namely the difference between shadow and market input prices. ${ }^{2}$ Considering $I$ firms $(i=1, \ldots, I)$ and $T$ periods $(t=1, \ldots, T)$ the short-run cost function could be defined as follows:

$$
\ln \left(V C_{i t}\right)=T L\left(Y_{i t}, \overrightarrow{W_{l t}}, K_{i t}, \overrightarrow{Z_{l t}}, t ; \vec{\beta}\right)+v_{i t}+u_{i t}
$$

\footnotetext{
${ }^{2}$ Kumbhakar (1992) finds evidence of labour overutilization among US carriers in the period immediately following the US deregulation. Bitzan et al. (2014) analyse a longer post-deregulation period and points out that work rules rigidities inflate the price of labour above its market price leading to capital and fuel overutilization by US airlines.
} 


\section{Please cite as:}

\section{Scotti, D., Volta, N. (2017). Profitability Change in the Global Airline Industry. Transportation Research Part E, 102, 1-12.}

where $v_{i t}$ is the common error component independently and identically distributed as $N\left(0, \sigma_{v}^{2}\right)$, while $u_{i t}$ is the time varying inefficiency term estimated as $u_{i t}=$ $\exp (\eta(t-T)) * u_{i}$ (Battese and Coelli, 1992) with $u_{i} \sim E(\lambda) .{ }^{3}$ Analysing the estimated eta $(\eta)$, it is possible to observe if the industry is on average increasing (negative eta) or decreasing (positive eta) the cost efficiency level.

Our specification involves a non-neutral and non-monotonic time trend. In order to be consistent with the cost minimization, the short-run cost function needs to satisfy the common conditions of non-negativity in costs, non-decreasing in input prices and in output, homogeneity and concavity. While the homogeneity condition can be easily included by normalizing both input prices and the short-run costs by one of the input prices, the monotonicity and the concavity conditions, especially, are not easily implementable in the estimation. The Cholesky decomposition method introduced by Lau (1976) is widely used to impose economic regularity, however it could destroy the flexibility properties of the functional form and it is not always possible to ensure that the regularity conditions are satisfied (Coelli et al., 2006). In order to avoid these difficulties, it is common practice to estimate an unrestricted model to assess the violations severity ex-post. However, ignoring the concavity violations could lead to unreliable results (Chua et al., 2005). ${ }^{4}$ Viable alternatives are to impose local concavity involving a reparameterization (Ryan and Wales 2000) or to implement an accept/reject algorithm into a Bayesian estimation framework (Terrell, 1996). In this research we use the latter method since its relative easiness to be implemented into a stochastic framework. As noted in van den Broeck et al. (1994), and lately reported by Griffin and Steel (2007), the advantages of applying a Bayesian estimations for the stochastic frontier methods are (i) the exact inference on the inefficiencies, (ii) the easy incorporation of regularity conditions and (iii) the inclusion of probability statements on unknown parameters presenting the results in terms of probability density functions.

\subsection{Total factor productivity and Profitability}

Starting from the short-run cost function defined as in the previous section, we compute the total factor productivity, the profitability and their respective decompositions. Following the approach based on derivatives proposed by Kumbhakar et al. (2015) so that total factor productivity (TFP) change can be computed as follows:

$$
T \dot{F} P=-\frac{\partial u_{i t}}{\partial t}-\frac{\partial \ln \left(V C_{i t}\right)}{\partial t}+\dot{y}\left(1-R T S^{-1}\right)-\frac{\partial \ln \left(V C_{i t}\right)}{\partial K} \dot{K}
$$

Where the first term is the efficiency change (EC), the second is the technical change (TC), the third is the scale efficiency change (SEC), while the last component takes

\footnotetext{
${ }^{3}$ We attempted to estimate the inefficiency term following the two approaches presented in Cuesta (2000) and Kumbhakar (1990) in order to improve the flexibilities in the inefficiencies computations. However, given the low estimation performance due to the increased number of parameters we decided to apply the more parsimonious Battese and Coelli approach.

${ }^{4}$ In our case, the estimation of the unrestricted model led to concavity violations for more than $50 \%$ of the observations.
} 


\section{Please cite as:}

\section{Scotti, D., Volta, N. (2017). Profitability Change in the Global Airline Industry. Transportation Research Part E, 102, 1-12.}

into account the quasi-fixed input (i.e. capital). The estimates of the short-run cost stochastic function are essential in the computation (and decomposition) of the total factor productivity. Specifically, the EC term is the partial derivative of the time varying inefficiency term $\left(u_{i t}\right)$, the TC and the quasi fixed input term are the partial derivatives of the estimated short-run cost function, while the SEC considers the function elasticities in the returns to scale (RTS).

Total factor productivity values are then used in order to express the change in profits as a percent of variable costs (profitability change) which is computed as:

$$
\frac{1}{V C} \frac{d \pi}{d t}=\frac{R e v}{V C} \dot{p}+\left(\frac{R e v}{V C}-1\right) \dot{y}-\sum_{j} S_{j}^{a} \dot{w}_{j}+T \dot{F} P
$$

where $R e v$ is the firm revenue, $V C$ the variable costs, $p$ the output price, $y$ the output quantity, $S$ the input share, while $w$ the input price. A dot over a variable indicates its rate of change. Profitability change is composed by the output price change (first term), the output quantity change (second term), the input price change (the third) and the total factor productivity change computed as in equation (3). Equations (3) and (4) are evaluated for each airline considered and in each period $t$ and $t+1$ (for further information on the profitability decomposition, see also Kumbhakar, 2015).

\section{Data}

Our unbalanced panel dataset includes 53 airlines and covers the period 1983-2010. Given the data available, we focus on the top airlines for each decade embracing most of the largest carriers in terms of passengers in 1983, 1990, 2000, and 2010. These include airlines that ceased operating and new carriers that entered in the market over the time period. The primary data sources include the digest of statistics from the International Civil Aviation Organization - ICAO data+ - and the International Air Transport Association yearly publication - IATA WATS. Information on datasets, observation periods and missing observations are provided in Appendix A. Subsidiaries are not included and, in the case of code sharing flights, traffic is allocated to the operating airline. ${ }^{5}$ Unfortunately, a lack of financial data prevented the inclusion of the main Middle East (e.g. Emirates, Etihad and Qatar) and Chinese carriers. Nevertheless, the panel data include 857 annual observations over 31 years, involving 15 North American, 16 European, 14 Asian Pacific, 5 Latin American, 2 Middle East and 1 African carriers. Prices, costs and revenues data are reported in US dollars and deflated by US GDP deflator sourced from the World Bank.

To estimate the cost function we consider the variable cost (VC) computed as the sum of the flight and cabin crew salaries and expenses (including benefits), the operating expenses for aircraft fuel and oil, and the cost of materials. Cost of material is obtained by subtracting labour, fuel and capital costs from the operating costs, hence including different cost categories such as maintenance costs, incidental transportrelated expenses, airport and air navigation charges, etc. Following Oum and $\mathrm{Yu}$ (1998), we consider as airline output the scheduled and not scheduled passengers

\footnotetext{
${ }^{5}$ The use of code-sharing agreement is of primarily importance in the industry for the generation of revenues and passenger (Brueckner, 2001). The data provided by ICAO and IATA allocate traffic, revenue and costs of code-sharing flights to the operating airline avoiding any biased measure.
} 


\section{Please cite as:}

\section{Scotti, D., Volta, N. (2017). Profitability Change in the Global Airline Industry. Transportation Research Part E, 102, 1-12.}

service (measured in revenue ton kilometres, RTK), cargo and mail scheduled service (measured in RTK) and the incidental services (measured as quantity index). ${ }^{6}$ The quantity index is obtained as the incidental revenues deflated by a general price index constructed using the purchase power parity index (PPP) and the US GDP deflator (both sourced from the World Bank). In order to include all the outputs and to reduce the number of parameters to estimate, we constructed a multilateral translog output index according to the procedure proposed by Caves et al (1982) and applied also by, among others, Windle and Dresner (1992), Oum and Yu (1995) and (1998). The index is computed as follows:

$$
\ln Y_{i}=\frac{1}{2} \sum_{s}\left(R_{i s}+\bar{R}_{S}\right)\left(\ln Y_{i s}-\overline{\ln Y_{s}}\right)
$$

Where $Y_{i}$ is the resulting aggregate output for airline $i, R_{i s}$ is the share of total revenues accounted by output $s$ for airline $i$ while $\bar{R}_{s}$ is the arithmetic mean of the revenue share of output $s$. Finally, $Y_{i s}$ is the output $s$ for airline $i$ and $\overline{\ln Y_{s}}$ is the arithmetic mean of the logarithm of output $s$. Labour input prices are computed as the average salary (fringe benefits included) per flight and cabin crew (pilots, co-pilots and cabin crew). ${ }^{7}$ As a proxy for material price, we use a general price index computed as the multiplication between PPP index and the US dollar deflator. With respect to the fuel input, we were not able to retrieve the fuel price at airline level neither the quantity of fuel consumed in the period considered. As a proxy, we therefore used the yearly average market price of crude oil as dollar per barrel gathered from the international monetary fund and the U.S. Department of Energy. In order to emphasize the prices differences between continents, we used the Brent crude oil price for European airlines, the West Texas Intermediate price for North American airlines, the Dubai Crude for Asian airlines while the OPEC crude oil price for the rest of the world. In order to validate our choice, we collected the yearly jet fuel price indices per continent provided by IATA/Platt, from 2004 to 2013. Data analysis shows a high significant correlation for each continent (around 0.98) between jet fuel and crude oil prices highlighting a very similar variation during the period analysed. Generally, the crude oil prices are on average 16 dollars per barrel lower than the jet fuel prices, hence leading to a possible magnitude underestimation of the relative cost function parameter. Drawbacks associated with the use of oil prices are that (i) the fuel variable has low variability (which we mitigate by using different oil prices) and (ii) the effects of fuel hedging strategies are not considered. However, the impact (if any) of the fuel hedging practise over our results is not clear. The main reasons are that (i) fuel hedging is not necessarily profitable (e.g. in the case of falling fuel price), (ii) hedging may have an insignificant impact over operating costs (Lim and Hong, 2014) and (iii) the expected value of a fuel hedge is null (Morrel and Swan 2006). Concerning our measure of capital, we use airline operating property and equipment

\footnotetext{
${ }^{6} \mathrm{RTK}$ is a common unit of measure in air transportation computed by multiplying the weight in tons of | the passengers/freight being transported by the number of kilometres that it is transported.

7 We acknowledge that when considering a short run cost function, crew members may be considered as quasi-fixed input (as for the capital input) since they are trained to operate specific aircraft and they cannot be easily incremented (or dismissed). However, we follow the extant literature considering a year an enough long period of time to be able to adjust the staff input to the optimum level.
} 


\section{Please cite as:}

\section{Scotti, D., Volta, N. (2017). Profitability Change in the Global Airline Industry. Transportation Research Part E, 102, 1-12.}

(i.e. flight equipment, ground equipment and properties, and land) similarly to Zou and Hansen (2012). As suggested in Oum and Zhang (1991), we correct the capital input by multiplying the capital stock by the utilization rate (i.e. airline average load factor). As often appearing in the literature, we gathered the average stage length and the number of destination to capture airline characteristics and to compute economies of scale and density (Caves et al. 1984). Finally, the data used to compute the total factor productivity (equation 3) and the profitability index (equation 4) are the same used for the cost function. Table 1 summarizes the variables used in the analysis providing descriptive statistics.

Table 1 - Data descriptive statistics

\begin{tabular}{|c|c|c|c|c|}
\hline & Mean & St.dev & Min & Max \\
\hline \multicolumn{5}{|l|}{ Output quantities } \\
\hline $\begin{array}{c}\text { Passengers } \\
\text { ('000 RTK) }\end{array}$ & $4,264,503$ & $4,159,033$ & 171,336 & $20,359,818$ \\
\hline $\begin{array}{c}\text { Freight } \\
\text { ('000 RTK) }\end{array}$ & $2,065,660$ & $2,860,850$ & - & $17,607,798$ \\
\hline $\begin{array}{c}\text { Mail } \\
\text { ('000 RTK) }\end{array}$ & 120,084 & 153,038 & - & 950,038 \\
\hline $\begin{array}{l}\text { Others } \\
(* 000 \text { US \$) }\end{array}$ & 491,548 & 836,199 & - & $6,366,713$ \\
\hline $\begin{array}{c}\text { Y - Aggregated output } \\
\text { (multilateral index) }\end{array}$ & 0.07 & 1.08 & 2.96 & 2.14 \\
\hline
\end{tabular}

\begin{tabular}{|c|c|c|c|c|}
\hline $\begin{array}{c}\text { Rev - Revenues } \\
\text { ('000 US \$) }\end{array}$ & & & & \\
\hline Passengers & $5,425,823$ & $4,891,657$ & 259,694 & $21,732,607$ \\
\hline Freight & 507,623 & 547,781 & - & $3,400,006$ \\
\hline Mail & 82,173 & 154,627 & - & $1,364,791$ \\
\hline Others & 599,375 & 938,159 & - & $6,859,584$ \\
\hline $\begin{array}{c}\text { TR - Total Revenues } \\
\text { ('000 US \$) }\end{array}$ & $6,614,994$ & $5,808,290$ & 284,992 & $25,367,468$ \\
\hline $\begin{array}{c}\begin{array}{c}\text { VC-Variable Costs } \\
\text { ('000 US \$) }\end{array} \\
\end{array}$ & $5,703,289$ & $5,139,113$ & 188,463 & $26,118,140$ \\
\hline
\end{tabular}

\begin{tabular}{|c|r|r|r|r|}
\hline W - Input prices & & & 20.93 & 483.93 \\
\hline $\begin{array}{c}\text { Labour } \\
\text { ('000 US \$) }\end{array}$ & 123.75 & 58.28 & 16.39 & 107.39 \\
\hline $\begin{array}{c}\text { Fuel } \\
\text { (US \$) }\end{array}$ & 40.18 & 20.22 & 0.22 & 2.64 \\
\hline Material & 1.23 & 0.55 & 33,062 & $29,406,285$ \\
\hline
\end{tabular}

\section{Results}

We estimate the equation (2) on the data presented in section (3) by applying a Bayesian approach. Prior specifications for the parameters are introduced following Griffin and Steel (2004b). The estimation results are based on the 60,000 retained draws with a thinning to every $5^{\text {th }}$ draw after a burn in of 40,000 iterations. With the exception of the time trend, all variables are mean corrected prior to the estimation 


\section{Please cite as:}

Scotti, D., Volta, N. (2017). Profitability Change in the Global Airline Industry. Transportation Research Part E, 102, 1-12.

allowing first-ordered parameters to be interpreted as elasticities at the sample mean. Material price is used as the normalization variable. Table 2 shows the short-run cost function estimated parameters (i.e. posterior mean), standard deviation and the $95 \%$ confidence interval. ${ }^{8}$

Table 2 - Cost function estimates

\begin{tabular}{|c|c|c|c|c|c|}
\hline & Mean & Std & $2.50 \%$ & Median & $97.50 \%$ \\
\hline Intercept & -0.518 & 0.067 & -0.660 & -0.516 & -0.394 \\
\hline Labour Price (w_l) & 0.484 & 0.049 & 0.391 & 0.484 & 0.578 \\
\hline Fuel Price (w_f) & 0.124 & 0.029 & 0.069 & 0.123 & 0.184 \\
\hline Capital (k) & 0.013 & 0.036 & -0.058 & 0.012 & 0.082 \\
\hline Output (y) & 0.705 & 0.054 & 0.602 & 0.703 & 0.810 \\
\hline Destinations (de) & 0.176 & 0.041 & 0.095 & 0.176 & 0.256 \\
\hline Stage length (avg) & 0.070 & 0.069 & -0.062 & 0.069 & 0.210 \\
\hline $\mathbf{w}_{-} \mathbf{l}^{\wedge} \mathbf{2}$ & 0.160 & 0.047 & 0.065 & 0.161 & 0.249 \\
\hline $\mathbf{w} \mathbf{f}^{\wedge} \mathbf{2}$ & 0.052 & 0.024 & 0.004 & 0.052 & 0.097 \\
\hline$k^{\wedge} 2$ & 0.056 & 0.019 & 0.019 & 0.057 & 0.093 \\
\hline y2 & 0.054 & 0.049 & -0.043 & 0.053 & 0.150 \\
\hline $\mathrm{de}^{\wedge} \mathbf{2}$ & 0.080 & 0.047 & -0.012 & 0.080 & 0.171 \\
\hline $\operatorname{avg}^{\wedge} 2$ & 0.047 & 0.091 & -0.129 & 0.046 & 0.228 \\
\hline $\mathbf{w} \_$l $* \mathbf{w}_{-} \mathbf{f}$ & 0.005 & 0.024 & -0.039 & 0.004 & 0.052 \\
\hline$\overline{\mathbf{w}} \mathbf{l} * \mathbf{k}$ & -0.003 & 0.017 & -0.036 & -0.003 & 0.032 \\
\hline $\mathbf{w} \_\mathbf{l} * \mathbf{y}$ & -0.097 & 0.032 & -0.160 & -0.096 & -0.038 \\
\hline w_l $*$ de & 0.047 & 0.026 & -0.008 & 0.049 & 0.095 \\
\hline w_l $*$ avg & 0.084 & 0.041 & 0.007 & 0.083 & 0.168 \\
\hline $\mathbf{w} \_$f $* \mathbf{k}$ & 0.034 & 0.014 & 0.006 & 0.034 & 0.060 \\
\hline $\mathbf{w} \_f^{\prime} * \mathbf{y}$ & -0.067 & 0.023 & -0.111 & -0.067 & -0.021 \\
\hline w_f $*$ de & -0.038 & 0.021 & -0.078 & -0.038 & 0.003 \\
\hline w_f ${ }^{*}$ avg & 0.098 & 0.025 & 0.049 & 0.097 & 0.148 \\
\hline $\mathbf{k} * \mathbf{y}$ & -0.026 & 0.025 & -0.075 & -0.026 & 0.024 \\
\hline $\mathbf{k} * \mathbf{d e}$ & -0.043 & 0.021 & -0.085 & -0.043 & -0.003 \\
\hline $\mathbf{k} *$ avg & -0.072 & 0.031 & -0.132 & -0.073 & -0.010 \\
\hline$y *$ de & -0.055 & 0.033 & -0.120 & -0.055 & 0.011 \\
\hline y*avg & 0.048 & 0.055 & -0.059 & 0.048 & 0.158 \\
\hline de * avg & 0.167 & 0.048 & 0.072 & 0.167 & 0.258 \\
\hline time (t) & 0.028 & 0.006 & 0.016 & 0.028 & 0.039 \\
\hline$t^{\wedge} 2$ & -0.002 & 0.000 & -0.003 & -0.002 & -0.002 \\
\hline $\mathbf{t} * \mathbf{w} \_\mathbf{l}$ & -0.012 & 0.003 & -0.018 & -0.012 & -0.007 \\
\hline $\mathbf{t} * \mathbf{w} \_\mathbf{f}$ & 0.009 & 0.002 & 0.005 & 0.009 & 0.012 \\
\hline $\mathbf{t} * \bar{k}$ & 0.004 & 0.002 & 0.000 & 0.004 & 0.008 \\
\hline $\mathbf{t} * \mathbf{y}$ & 0.003 & 0.003 & -0.004 & 0.003 & 0.009 \\
\hline$t *$ de & -0.005 & 0.002 & -0.009 & -0.005 & 0.000 \\
\hline t*avg & -0.010 & 0.004 & -0.018 & -0.010 & -0.003 \\
\hline Eta $\eta$ & -0.008 & 0.005 & -0.017 & -0.008 & 0.000 \\
\hline
\end{tabular}

\footnotetext{
8 Posterior densities (obtainable upon request to the authors) show estimations convergence. We remind to the reader that regularity requirements are a-priori satisfied since imposed during the estimation approach.
} 


\section{Please cite as:}

\section{Scotti, D., Volta, N. (2017). Profitability Change in the Global Airline Industry. Transportation Research Part E, 102, 1-12.}

Most of the variables are significant and present the expected signs. The only exceptions are the capital and the stage length that are not significant at the first order. The elasticities of cost with respect to the factor prices are equivalent to shares in variable costs. At the sample mean, labour account for approximately $48 \%$ of airline variable costs while fuel accounts for the $12 \%$ leaving the materials cost to around $40 \%$. We need to bear in mind that the fuel price is the crude oil price and not the jet fuel price. If the real jet fuel price were used, we would expect a higher magnitude of the price factor. ${ }^{9}$ As expected, we find a positive relation between the outputs and the variable costs. Specifically, an increase of $1 \%$ in the output level leads to a $0.7 \%$ increase in variable costs. The first order coefficient of the time trend is positive and statistically significant, while the squared term is negative and significant indicating that the variable costs are increasing at a decreasing rate during the period considered. Following Caves et al. (1984), the estimated elasticities allow the computation of the economies of traffic density $\left(R T D=\left(1-\epsilon^{k}\right) /\left(\epsilon^{y}\right)=1.4\right)$ and the economies of scale $\left.R T S=\left(1-\epsilon^{k}\right) /\left(\epsilon^{y}+\epsilon^{d e}\right)=1.12\right)$. At the average, our estimations show returns to scale close to the unity while indicating increasing return to density. Our findings are in line with most of the existing literature (for an exhaustive comparison of RTD and RTS estimations see Jara-Diaz et al., 2014). When analysing the efficiency results, the negative and significant estimated eta (-0.008) shows that average airline slightly improves its variable cost efficiency. As reported in Table 3, the overall industry cost efficiency is 0.70 increasing from the 0.67 of 1983 to the 0.73 of 2010 . We notice that the yearly average efficiency values are not increasing eta-proportionally as expected, since our data set is unbalanced (i.e. missing values, ceased airlines and new entrants). Airlines efficiency estimates are reported in Appendix B.

Table 3 - Average efficiency estimates

\begin{tabular}{|l|c|c|c|c|c|c|c|c|}
\hline $\mathbf{1 9 8 3}$ & $\mathbf{1 9 8 4}$ & $\mathbf{1 9 8 5}$ & $\mathbf{1 9 8 6}$ & $\mathbf{1 9 8 7}$ & $\mathbf{1 9 8 8}$ & $\mathbf{1 9 8 9}$ & $\mathbf{1 9 9 0}$ & $\mathbf{1 9 9 1}$ \\
\hline 0.67 & 0.67 & 0.68 & 0.69 & 0.69 & 0.66 & 0.67 & 0.68 & 0.67 \\
\hline
\end{tabular}

\begin{tabular}{|l|c|c|c|c|c|c|c|c|}
\hline $\mathbf{1 9 9 2}$ & $\mathbf{1 9 9 3}$ & $\mathbf{1 9 9 4}$ & $\mathbf{1 9 9 5}$ & $\mathbf{1 9 9 6}$ & $\mathbf{1 9 9 7}$ & $\mathbf{1 9 9 8}$ & $\mathbf{1 9 9 9}$ & $\mathbf{2 0 0 0}$ \\
\hline 0.67 & 0.68 & 0.70 & 0.70 & 0.71 & 0.71 & 0.72 & 0.71 & 0.72 \\
\hline
\end{tabular}

\begin{tabular}{|c|c|c|c|c|c|c|c|c|c|}
\hline $\mathbf{2 0 0 1}$ & $\mathbf{2 0 0 2}$ & $\mathbf{2 0 0 3}$ & $\mathbf{2 0 0 4}$ & $\mathbf{2 0 0 5}$ & $\mathbf{2 0 0 6}$ & $\mathbf{2 0 0 7}$ & $\mathbf{2 0 0 8}$ & $\mathbf{2 0 0 9}$ & $\mathbf{2 0 1 0}$ \\
\hline 0.72 & 0.73 & 0.73 & 0.74 & 0.73 & 0.74 & 0.73 & 0.73 & 0.74 & 0.73 \\
\hline
\end{tabular}

Partial derivatives of the estimated short-run cost function are used in order to compute the total factor productivity (TFP) change and its decompositions as shown in Equation 3. In Table 4 we report the total factor productivity and its components as average over the full period. Although the mean and the median are really similar (and close to zero), the quartile values show variations. The airline industry registered an average yearly increase in productivity of around $0.1 \%$ with an increase in the efficiency $(0.3 \%)$ and in technical change $(0.9 \%)$. Remarkably, the scale efficiency

\footnotetext{
${ }^{9}$ Despite the use of crude oil prices, our estimates may be considered reasonable when compared to similar studies (e.g. 19.6\% Caves et al., 1984, 15\% Oum and Yu, 1998, 20\% Zou and Hansen, 2012).
} 


\section{Please cite as:}

Scotti, D., Volta, N. (2017). Profitability Change in the Global Airline Industry. Transportation Research Part E, 102, 1-12.

change is on average negative $(-0.7 \%)$ highlighting an average movement away the most productive scale size.

Table 4 - Total factor productivity and components

\begin{tabular}{|c|c|c|c|c|}
\cline { 2 - 5 } \multicolumn{1}{c|}{} & Mean & Quartile 1 & Median & Quartile 3 \\
\hline TFP & 0.001 & -0.017 & 0.002 & 0.020 \\
\hline EC & 0.003 & 0.002 & 0.003 & 0.004 \\
\hline TC & 0.009 & -0.005 & 0.012 & 0.024 \\
\hline Scale & -0.007 & -0.013 & -0.007 & 0.000 \\
\hline Capital change & -0.004 & -0.009 & -0.002 & 0.003 \\
\hline
\end{tabular}
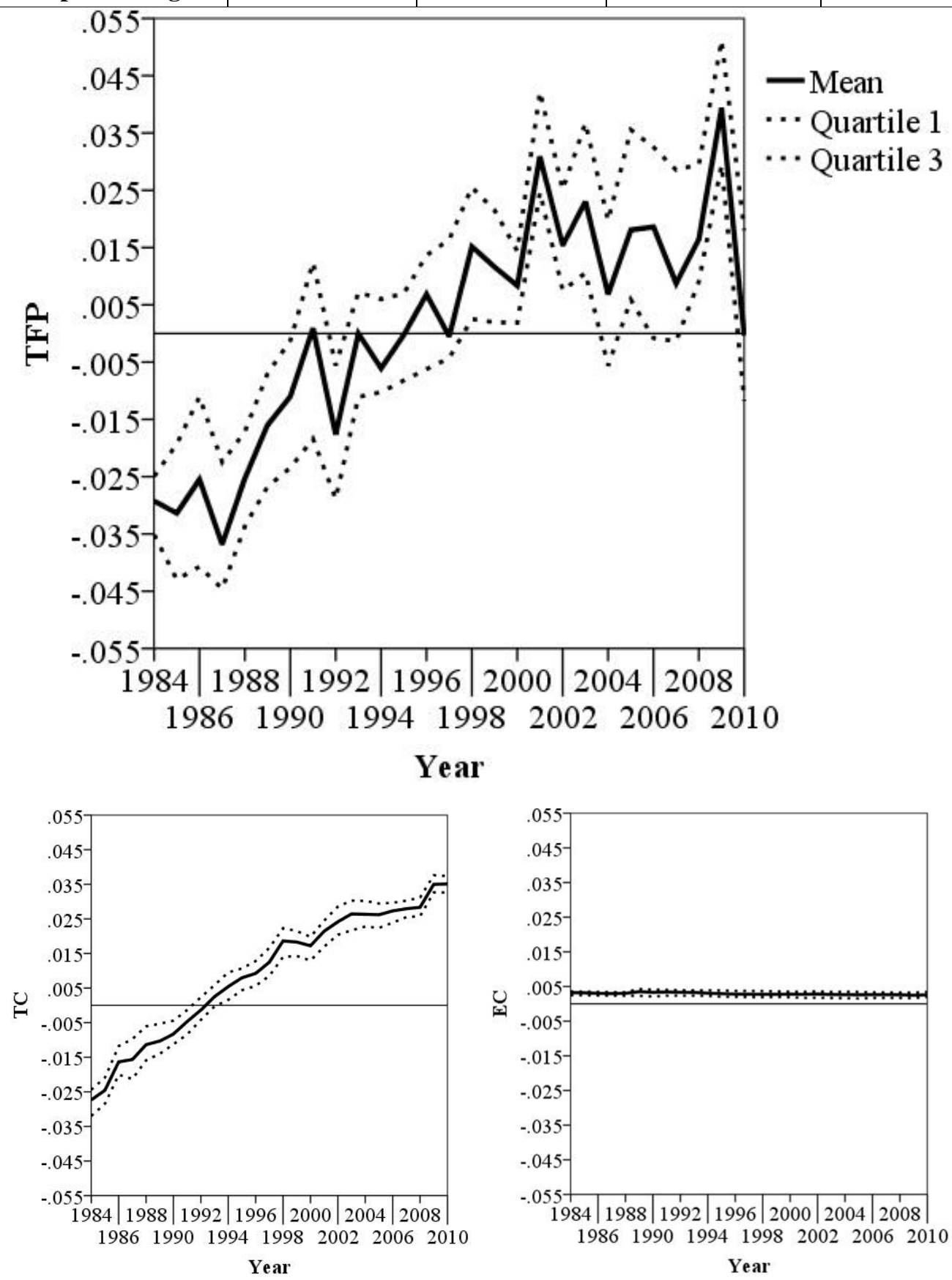


\section{Please cite as:}

Scotti, D., Volta, N. (2017). Profitability Change in the Global Airline Industry. Transportation Research Part E, 102, 1-12.
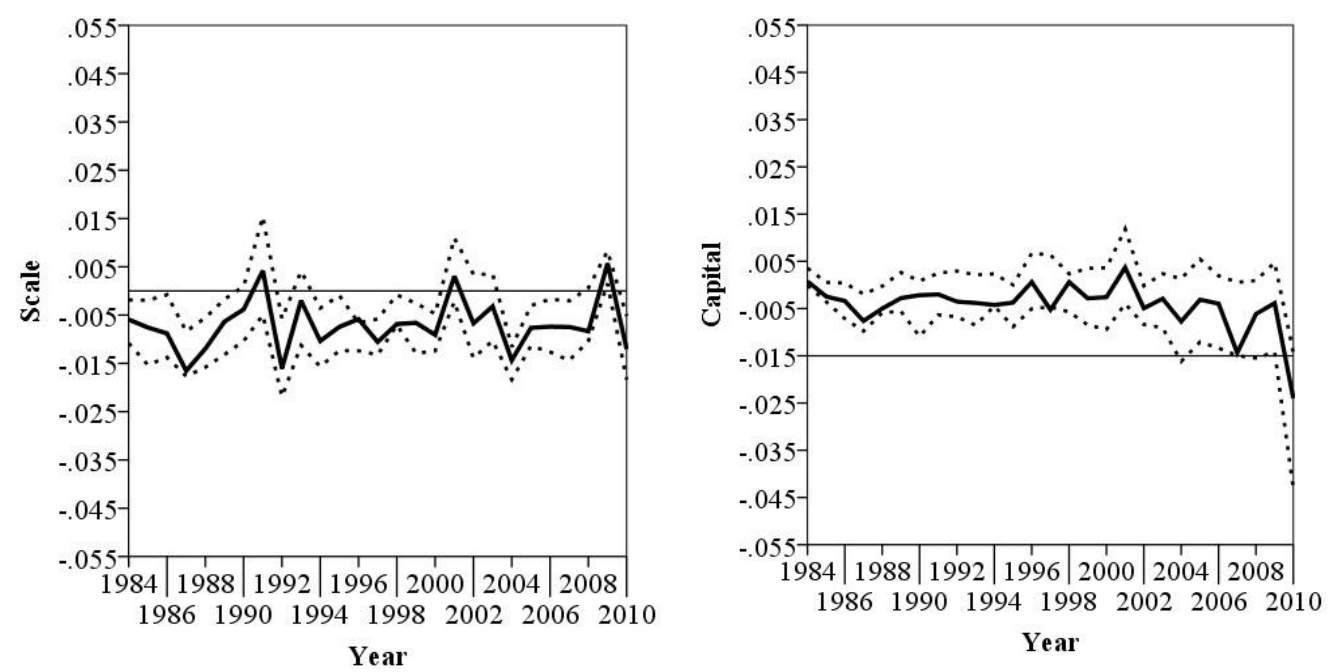

Figure 1 - Total factor productivity and decomposition yearly changes.

Figure 1 shows the yearly average change in productivity during the period and its indices decomposition. The index shows an increasing trend flattering in the last decade. The average total factor productivity remains negative until the first years of 1990s turning and then remaining positive for the rest of the period. Generally, it is not possible to recognize shocks or major variations in the period under analysis, with the only exception of the financial crisis years. Notably, despite the high variability during the financial crisis the index remains positive highlighting an increase in total factor productivity. Analysing the index decomposition, the increasing trend is provided by the technical change component while stochasticity is given by the scale change and the capital change components. Efficiency change is acting as an upwards shifter remaining positive and flat during the all period. ${ }^{10}$ Generally, the variation between airline is limited as shown by the 1st and 3rd quartile lines (dotted lines) remaining close to the average line.

Equation 4 is used to compute the profitability change and its decomposition as shown in table 5 . The average on the full period shows a slightly negative change in the profitability with high variability within the period considered (inter-quantile range from $-6 \%$ to $+5 \%$ ). With respect to the components, the output factors show a $2 \%$ decrease in the price change while showing an average $1.4 \%$ increase in quantity change. While the output quantity change is homogeneous within the period, the output price change shows high variability ranging from a $-8 \%$ of the first quartile to the $+4 \%$ of the third quartile. Finally, the input price change registers a period average close to zero $(-0.3 \%)$ with an average variation between $-4 \%$ and $+4 \%$.

Table 5 - Profitability change and components

\begin{tabular}{|c|c|c|c|c|}
\hline & Mean & Quartile 1 & Median & Quartile 3 \\
\hline Profitability Change & -0.005 & -0.060 & -0.005 & 0.050 \\
\hline TFP & 0.001 & -0.017 & 0.002 & 0.020 \\
\hline Output Price & -0.023 & -0.082 & -0.018 & 0.041 \\
\hline Output Quantity & 0.014 & 0.000 & 0.007 & 0.021 \\
\hline Input Price & -0.003 & -0.035 & -0.002 & 0.036 \\
\hline
\end{tabular}

${ }^{10}$ The flat efficiency change is caused by our choice of using a unique eta for all the airlines. 


\section{Please cite as:}

\section{Scotti, D., Volta, N. (2017). Profitability Change in the Global Airline Industry. Transportation Research Part E, 102, 1-12.}

When studying the indices yearly variation (Figure 2), it is possible to depict more specifics results. TFP is found to be a non-trustworthy predictor of profitability as already highlighted in Windle and Dresner (1992). ${ }^{11}$ Indeed, the two indices have shown differences in trend, magnitude and variability. Despite the zero total average, the profitability - whose trend is consistent with the findings of Borenstein (2011) exhibits stochasticity between years and high intra-quantile variability within the years. Differently from total factor productivity, two main downturns corresponding to the 90s oil crisis, and the 2008 financial crisis can be recognized in the figure. However, while the 90s shock has a homogeneous effect on the whole industry with a relatively small inter-quantile range, the 2008 shock looks more heterogeneous with the profitability change ranging $10 \%$ points around the mean. The $9 / 11$ terrorist attack seems to have not affected the aviation industry specifically, but is likely to have contributed to the high variability of the early 2000s. Other events that may have affected the profitability change of those years are the European sky liberalization (increased competition with the start of several low cost carriers), the internet bubble and the SARS epidemic. Most of the index stochasticity is originated from the output price and the input price factors, while the output quantities and total factor productivity factors exhibit a lower degree of variability over the period. The output price and the input price change components show a similar pattern (especially in the last decade of the period). However, while the output price change is mostly greater than the input price change until the early 1990s (negative TFP change), such trend reverses when TFP change becomes positive (Figure 3). This may suggest that part of the airline productivity gains are passed to consumers in terms of lower (higher) fares increase (reduction). In these regard, policies aimed at increasing competition (e.g. open sky agreements) may have strengthened this effect by placing a downward pressure on the fares and enhancing productivity gains. This result contributes to the regulatory debate whether airlines succeed in passing through cost changes into their output price (see Koopmans and Lieshout, 2016 for an extensive literature review). Our figures may suggest that the pass through rate may be affected by airlines productivity changes. However, our results can be only observed as a general trend, indeed the input price change component seems homogeneous within the industry with all the airlines close to the average values, while the output price change component shows high heterogeneity. This may reflect the different competitive pressures faced by the airlines which, in turn, cause different pass through rates (e.g. Forsyth and Gillen, 2007). Finally, Figure 2 shows the dissimilarities in magnitude between the profitability and total factor productivity change, thus highlighting that the TFP contribution to the pass through rate may be generally small (if existing).

\footnotetext{
${ }^{11}$ We remind to the reader that the total factor productivity shown in Figure 2 is the same as the one in Figure 1 with the only difference in the y-axis scale.
} 
Please cite as:

Scotti, D., Volta, N. (2017). Profitability Change in the Global Airline Industry. Transportation Research Part E, 102, 1-12.
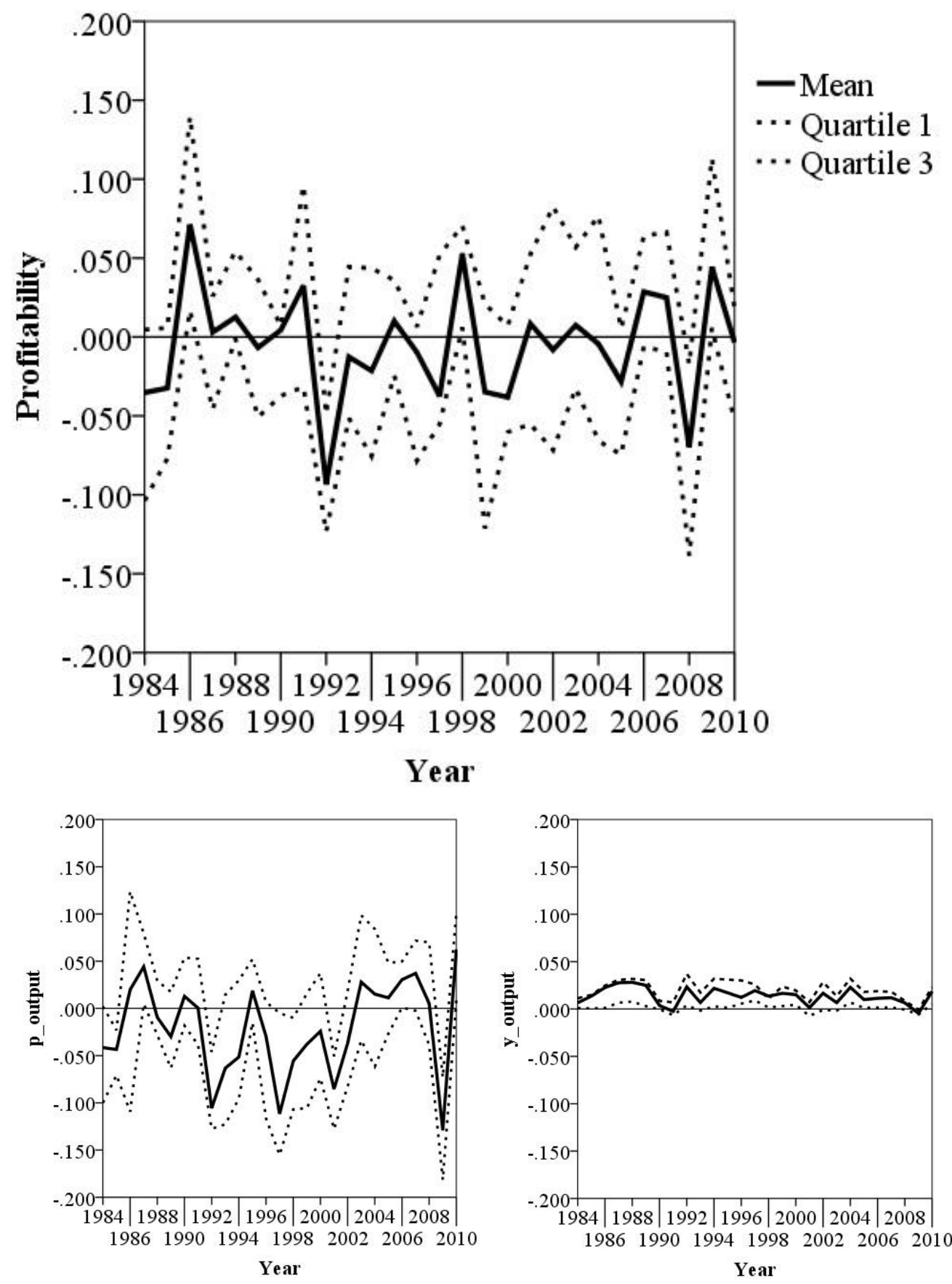
Please cite as:

Scotti, D., Volta, N. (2017). Profitability Change in the Global Airline Industry. Transportation Research Part E, 102, 1-12.
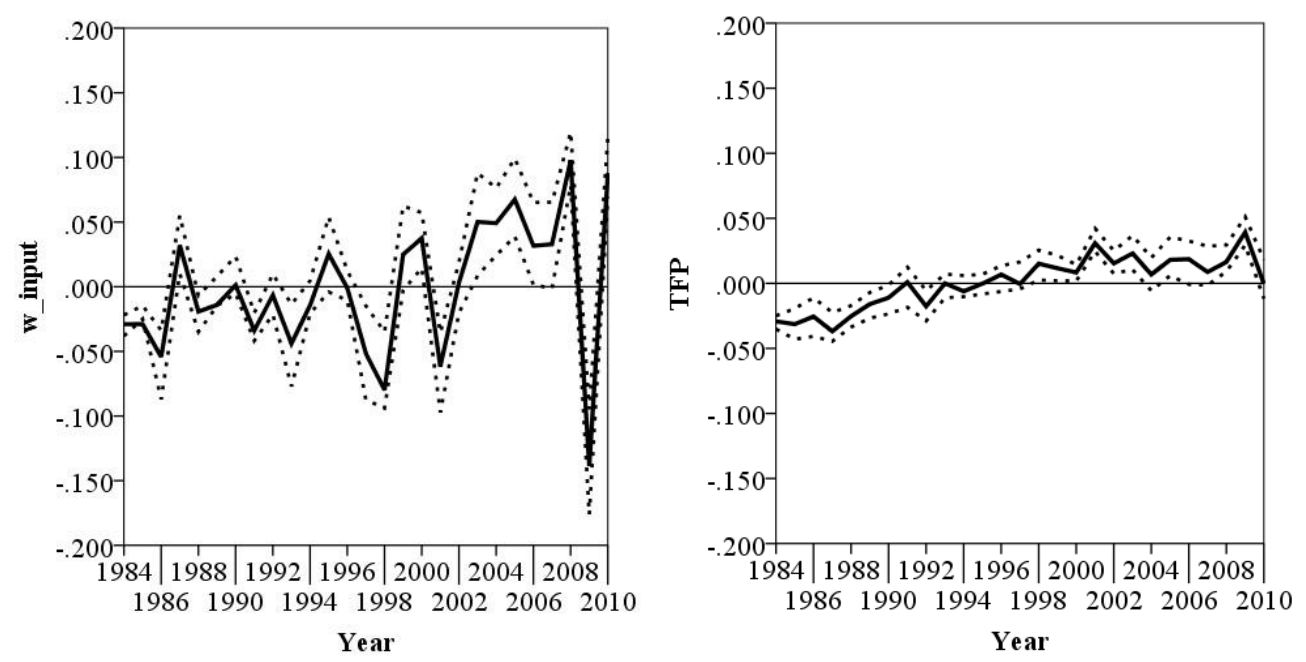

Figure 2 - Profitability change and decomposition yearly changes.

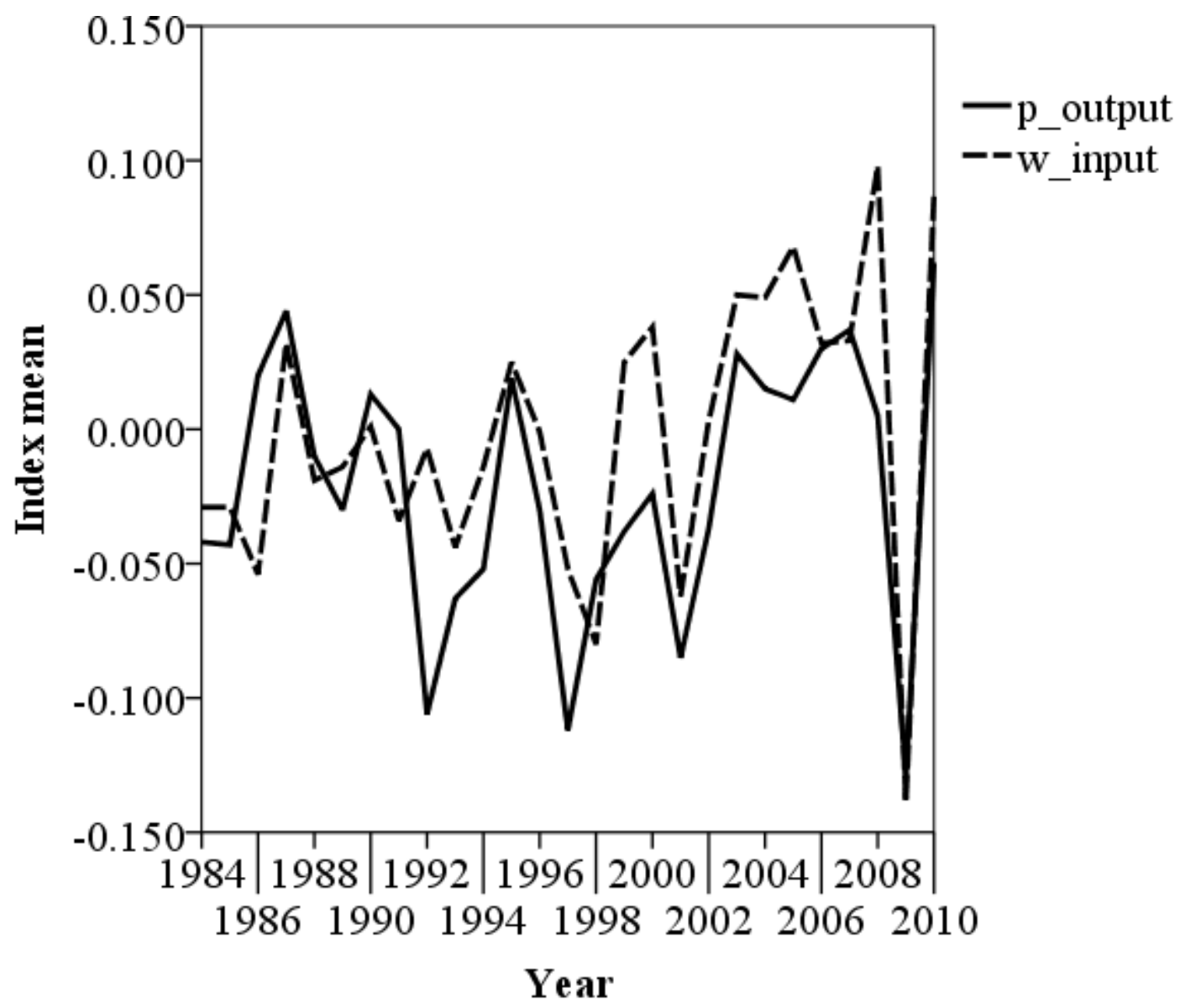

Figure 3 - Input and output price changes over time.

Figure 4 shows the relative importance of each factor (by year and decade) with respect to the profitability change index. Given the additive form of the profitability change index, we consider the absolute value of the specific driver and its proportional contribution to the profitability change value. On average, the output and the input price factors are the major components (both around $35 \%$ of the profitability 


\section{Please cite as:}

\section{Scotti, D., Volta, N. (2017). Profitability Change in the Global Airline Industry. Transportation Research Part E, 102, 1-12.}

change) with the share of the latter predominant during the shocks periods. Total factor productivity and output quantity factors are relatively less important, both accounting for around $15 \%$ of the average profitability change. Generally, there is a change in the relative importance over the period analysed. From a balanced contribution during the first decade, the figure shows a decreasing importance of TFP and output quantity factors in favour of the output price factor (during the 90s) and of the input price factor (last decade of the period). These results support the existing literature stating that airlines financial difficulties have occurred mainly due to (i) increasing market competition and (ii) growing operating costs. On the one hand, output price changes are strongly related to the competition levels; market entry threat and LCCs growth have exerted downward pressure on fares (Evans and Kessides, 1993; Franke 2004). On the other hand, volatile fuel prices (Franke and John, 2011) as well as increasing labour costs (Dennis, 2007) are the major factors pushing the change in input prices.
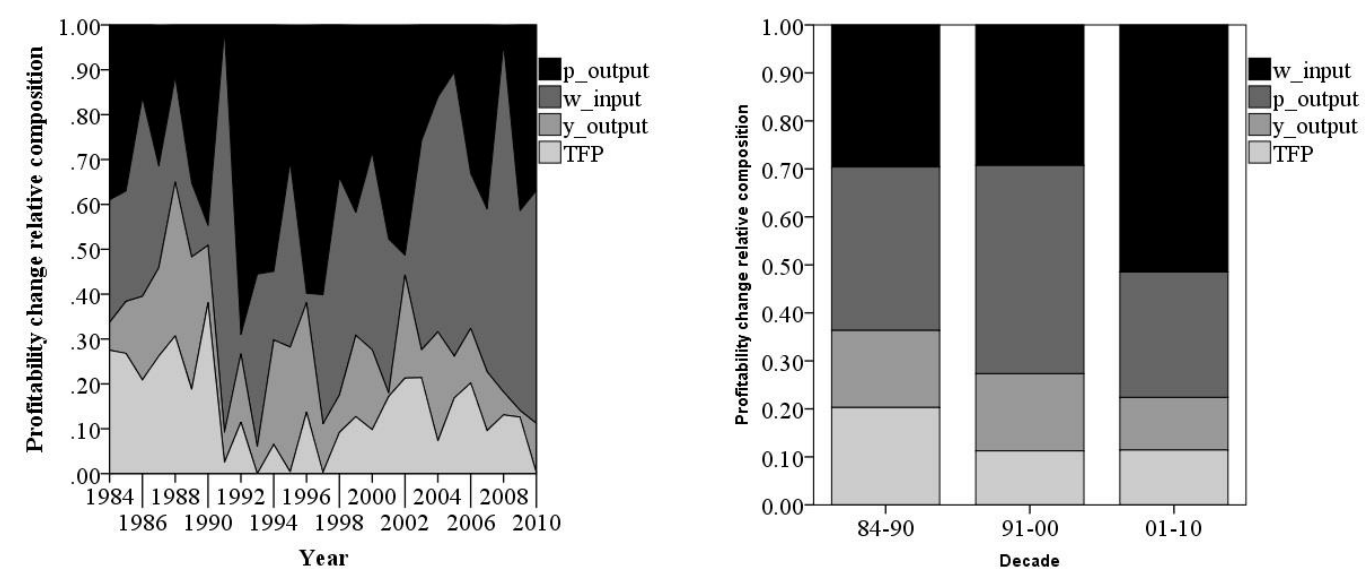

Figure 4 - Relative importance of profitability change components

\section{Conclusions}

This paper has analysed profitability change in the global airline industry. A Bayesian approach was applied to estimate a stochastic short-run cost function for 53 airlines in the period 1983-2010. Productivity and profitability changes have been determined together with their components.

The short-run cost function estimates show that variable costs are increasing at a decreasing rate, and that the average airlines benefits of almost constant returns to scale and increasing return to density. Overall we estimate an average 0.7 cost efficiency increasing from the 0.67 of 1983 to the 0.73 of 2010. On average, airline efficiency change increases almost constantly over time and productivity change is mainly driven by technical change, becoming positive from early 1990s. Our results confirm that total factor productivity cannot be considered as a good predictor of profitability. Indeed, profitability change seems to be mainly driven by input and output price changes, which show a similar pattern over time while having different degree of variability. However, TFP seems to maintain a certain degree of relevance in terms of both airlines profitability and possibly in terms of passengers benefit: the output price increase (reduction) is higher (lower) than the input price increase (reduction) when productivity decreases (TFP change is negative), and this relation 


\section{Please cite as:}

\section{Scotti, D., Volta, N. (2017). Profitability Change in the Global Airline Industry. Transportation Research Part E, 102, 1-12.}

reverses when productivity increases over time. This may suggest that, in presence of productivity gains, part of such gains is transferred from airlines to passengers in terms of lower output prices. In other words, total factor productivity change seems to influence airlines' passing through rate. This effect may vary among markets as suggested by the variability of the output price change index and may be limited given the differences in magnitude between TFP and profitability change.

Future works should investigate the cost function and the profitability change of small and regional airlines. Smaller scale size and the different market orientations may lead to differences in cost function estimates and in indices trends. However, the availability of data is a key limiting factor to possible comparable analysis on a global basis. Other possible extensions may empirically evaluate the effects of specific regulations over airline profitability. This would require the design of specific cost functions able to take into account the heterogeneous and exogenous characteristics of the different markets. Considering the different backgrounds and regulatory frameworks would provide targeted policy recommendations to foster the industry profitability.

\section{References:}

1) Barnhart C., Farahat A., Lohatepanont M., 2009. Airline fleet assignment with enhanced revenue modelling. Operations Research 57(1), 231-244.

2) Battese, G.E., Coelli, T.J., 1992. Frontier production functions, technical efficiency and panel data with application to paddy fanners in India. Journal of Productivity Analysis 3, 153-169.

3) Bitzan, J., Peoples, J., 2014. US air carriers and work-rule constraints-Do airlines employ an allocatively efficient mix of inputs?. Research in Transportation Economics 45, 9-17.

4) Borenstein, S., 2011. Why can't US airlines make money?. The American Economic Review 101(3), 233-237.

5) Brueckner, J.K., 2001. Economics of International codesharing: an analysis of airline alliances among others. International Journal of Industrial Organization 19(10), 1475-1498.

6) Brugnoli, A., Button, K., Martini, G., Scotti, D., 2015. Economic factors affecting the registration of lower $\mathrm{CO} 2$ emitting aircraft in Europe. Transportation Research Part D: Transport and Environment 38, 117-124.

7) Button, K., 2005. How Stable are Scheduled Air Transport Markets?. Research in Transportation Economics 13, 27-48.

8) Button, K., McDougall, G., 2006. Institutional and structure changes in air navigation service-providing organizations. Journal of Air Transport Management 12(5), 236-252.

9) Caves, D.W., Christensen, L.R., Diewert, W.E., 1982. Multilateral comparisons of output, input, and productivity using superlative index numbers. Economic Journal 92, 73-86. 


\section{Please cite as:}

Scotti, D., Volta, N. (2017). Profitability Change in the Global Airline Industry. Transportation Research Part E, 102, 1-12.

10) Caves, D.W., Christensen, L.R., Tretheway, M.W., 1984. Economies of density versus economies of scale: why trunk and local service airline costs differ. Rand Journal of Economics 15, 471-489.

11) Chua, C.L., Kew, H. Yong, J., 2005. Airline code-share alliances and costs: imposing concavity on translog cost function estimation. Review of Industrial Organization 26, 461-487.

12) Coelli, T.J., Prasada Rao, D.S., Battese, G.E. 2006. An introduction to efficiency and productivity analysis. Springer Science \& Business Media.

13) Cuesta, R., 2000. A production model with firm specific temporal variation in technical inefficiency: with application to Spanish dairy farms. Journal of Productivity Analysis 13, 139-158.

14) Dennis, N., 2007. End of the free lunch? The responses of traditional European airlines to the low-cost carrier threat. Journal of Air Transport Management 13(5), 311-321.

15) Evans, W. N., Kessides, I. N., 1993. Localized market power in the US airline industry. The Review of Economics and Statistics 66-75.

16) Forsyth, P., Gillen, D., November 2007. Climate Change Policies and Impacts on Air Fares. GARS Workshop Cologne, pp. 28-29.

17) Franke, M., 2004. Competition between network carriers and low-cost carriers - retreat battle or breakthrough to a new level of efficiency?. Journal of Air Transport Management 10(1), 15-21.

18) Franke, M., John, F., 2011. What comes next after recession?-Airline industry scenarios and potential end games. Journal of Air Transport Management 17(1), 19-26.

19) Gillen, D.W., Oum, T.H., Tretheway, M.W., 1990. Airline cost structure and policy implications: a multi-product approach for Canadian airlines. Journal of Transport Economics and Policy 24, 9-34.

20) Good, D.H., Röller, L.H., Sickles, R.C., 1995. Airline efficiency differences between Europe and the US: implications for the pace of EC integration and domestic regulation. European Journal of Operational Research 80(3), 508518.

21) Griffin, J.E., Steel, M.F.J., 2004b. Flexible mixture modelling of stochastic frontier frontiers. Technical Report, University of Warwick.

22) Griffin, J.E., Steel, M.F.J., 2007. Bayesian stochastic frontier analysis using WinBUGS. Journal of Productivity Analysis 27, 163-176.

23) Heshmati, A., Kim, J., 2016. Stochastic Frontier Cost Function Model Specification and Estimation Results. In Efficiency and Competitiveness of International Airlines (pp. 123-163). Springer Singapore.

24) IATA (2013). Profitability and the air transport value chain. IATA Economics Briefing, 


\section{Please cite as:}

\section{Scotti, D., Volta, N. (2017). Profitability Change in the Global Airline Industry. Transportation Research Part E, 102, 1-12.}

https://www.iata.org/whatwedo/Documents/economics/profitability-and-theair-transport-value\%20chain.pdf

25) Jara-Díaz, S.R., Cortés, C.E., Morales, G.A. 2013. Explaining changes and trends in the airline industry: Economies of density, multiproduct scale, and spatial scope. Transportation Research Part E: Logistics and Transportation Review, 60, 13-26.

26) Koopmans, C., Lieshout, R. 2016. Airline cost changes: To what extent are they passed through to the passenger? Journal of Air Transport Management,53, 1-11.

27) Kumbhakar, S.C., 1990. Production frontiers, panel data and time-varying technical inefficiency. Journal of Econometrics 46, 201-211.

28) Kumbhakar, S. 1992. Allocative Distortions, Technical Progress, and Input Demand in U.S. Airlines: 1970-1984. International Economic Review 33(3), 723-737.

29) Kumbhakar, S.C., Wang, H., Horncastle, A.P., 2015. A Practitioner's Guide to Stochastic Frontier Analysis Using Stata. Cambridge University Press.

30) Lau, L.J., 1976. Applications of profit functions. M. Fuss and D. L. Mcfadden (eds) Production Economics: A Dual Approach to Theory and Application Volume I: The Theory of Production. North Holland: Elsevier.

31) Lawton, T. C., 2002. Cleared for take-off: structure and strategy in the low fare airline business. Ashgate Publishing Ltd.

32) Lim, S. H., Hong, Y., 2014. Fuel hedging and airline operating costs. Journal of Air Transport Management 36, 33-40

33) Morrell, P., Swan, W., 2006. Airline jet fuel hedging: Theory and practice. Transport Reviews, 26(6), 713-730.

34) Oum, T.H., Zhang, Y., 1991. Utilization of quasi-fixed inputs and estimation of cost functions. Journal of Transport Economics and Policy 25, 121-134.

35) Ryan, D.L., Wales, T.J., 2000. Imposing local concavity in the translog and generalized leontief cost functions. Economics Letters 67, 253-260.

36) Oum, T.H., Yu, C., 1995. A productivity comparison of the world's major airlines. Journal of Air Transport Management 2(3), 181-195.

37) Oum, T.H., Yu, C., 1998. Cost competitiveness of major airlines: an international comparison. Transportation Research Part A: Policy and Practice $32,407-422$

38) Oum, T.H., Yu, C., 2012. Winning airlines: Productivity and cost competitiveness of the world's major airlines. Springer Science \& Business Media. 


\section{Please cite as:}

Scotti, D., Volta, N. (2017). Profitability Change in the Global Airline Industry. Transportation Research Part E, 102, 1-12.

39) Scotti, D., Volta, N., 2015. An empirical assessment of the CO 2-sensitive productivity of European airlines from 2000 to 2010. Transportation Research Part D: Transport and Environment 37, 137-149.

40) Terrell, D., 1996. Incorporating monotonicity and concavity conditions in flexible functional forms. Journal of Applied Econometrics 11, 179-194.

41) the Economist (2014). Why airlines make such meagre profits. http://www.economist.com/blogs/economist-explains/2014/02/economistexplains-5

42) van den Broeck, J., Koop. G., Osiewalski, J., Steel, M.F.J., 1994. Stochastic frontier models: a Bayesian perspective. Journal of Econometrics 61, 273303.

43) Zou, B., Hansen, M., 2012. Impact of operational performance on air carrier cost structure: evidence from US airlines. Transportation Research Part E: Logistics and Transportation Review, 48, 1032-1048.

44) Windle, R.J., 1991. The world's airlines: a cost and productivity comparison. Journal of Transport Economics and Policy, 31-49.

45) Windle, R.J., Dresner, M.E., 1992. Partial productivity measures and total factor productivity in the air transport industry: limitations and uses. Transportation Research Part A: Policy and Practice, 26(6), 435-445.

46) Yu, C., 2016. Airline Productivity and Efficiency: Concept, Measurement, and Applications. John D. Bitzan, James H. Peoples, Wesley W. Wilson (ed.) Airline Efficiency (Advances in Airline Economics, Volume 5) Emerald Group Publishing Limited, 5, 11-53. 


\section{Please cite as:}

Scotti, D., Volta, N. (2017). Profitability Change in the Global Airline Industry.

Transportation Research Part E, 102, 1-12.

Appendix A: Missing observations are highlighted in red. When the cell is empty, the airline was still not founded or had already ceased the operations.

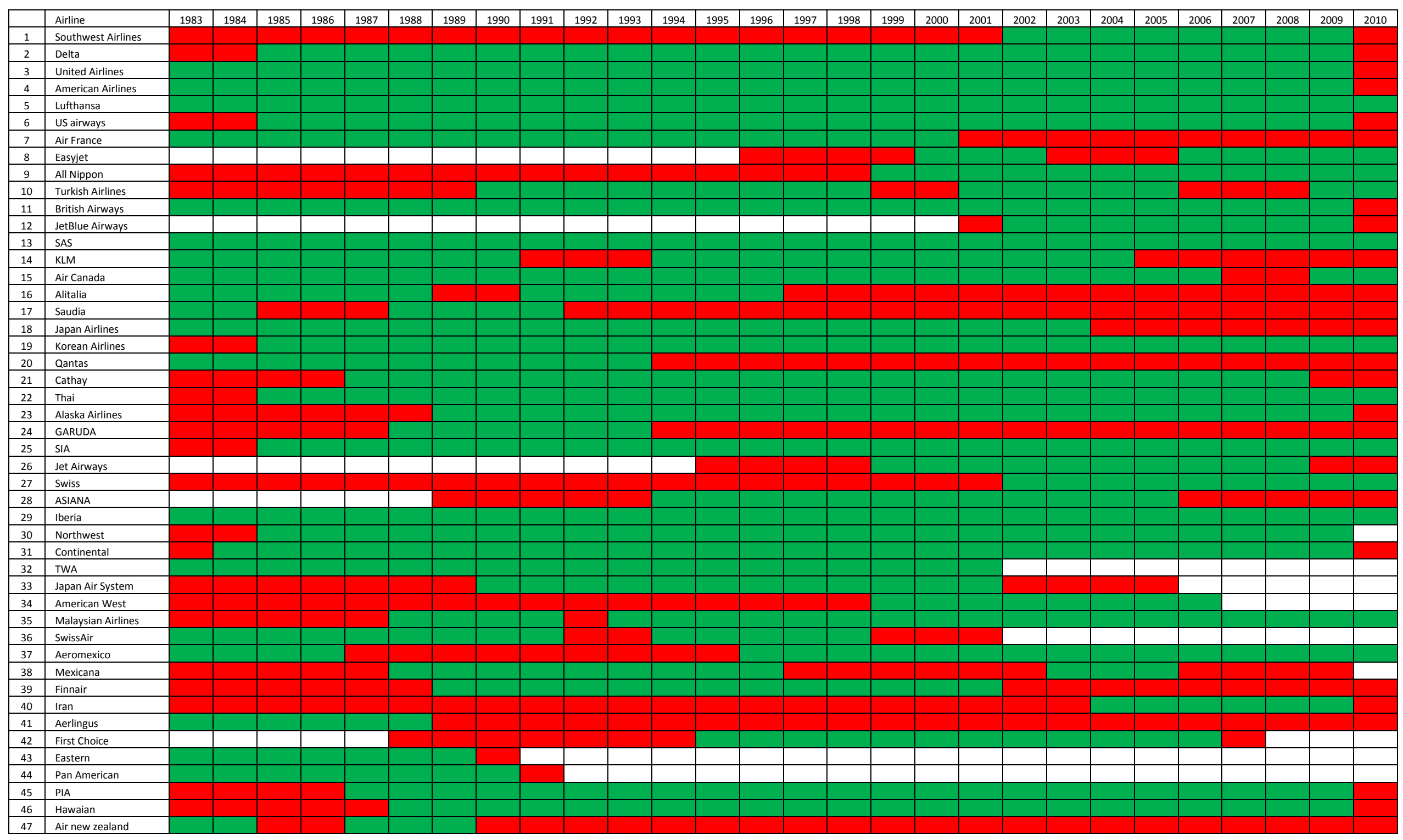




\section{Please cite as:}

Scotti, D., Volta, N. (2017). Profitability Change in the Global Airline Industry.

Transportation Research Part E, 102, 1-12.

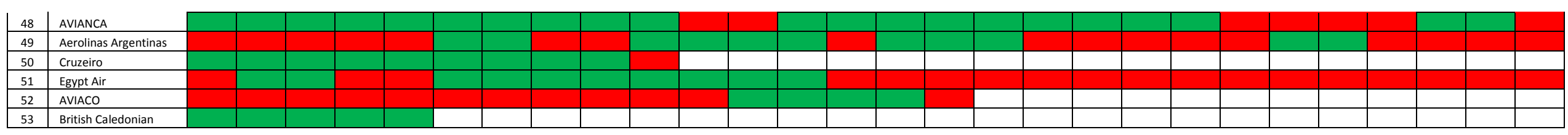




\section{Please cite as:}

\section{Scotti, D., Volta, N. (2017). Profitability Change in the Global Airline Industry.}

Transportation Research Part E, 102, 1-12.

Appendix B: Airlines efficiency scores

\begin{tabular}{|c|c|c|c|c|c|c|c|c|c|c|c|c|c|c|c|c|c|c|c|c|c|c|c|c|c|c|c|c|c|}
\hline & Airline & 1983 & 1984 & 1985 & 1986 & 1987 & 1988 & 1989 & 1990 & 1991 & 1992 & 1993 & 1994 & 1995 & 1996 & 1997 & 1998 & 1999 & 2000 & 2001 & 2002 & 2003 & 2004 & 2005 & 2006 & 2007 & 2008 & 2009 & 2010 \\
\hline 1 & Southwest Airlines & & & & & & & & & & & & & & & & & & & & 0.91 & 0.91 & 0.91 & 0.91 & 0.91 & 0.91 & 0.91 & 0.91 & \\
\hline 2 & Delta & & & 0.65 & 0.65 & 0.66 & 0.66 & 0.66 & 0.66 & 0.67 & 0.67 & 0.67 & 0.67 & 0.67 & 0.68 & 0.68 & 0.68 & 0.68 & 0.68 & 0.69 & 0.69 & 0.69 & 0.69 & 0.69 & 0.70 & 0.70 & 0.70 & 0.70 & \\
\hline 3 & United Airlines & 0.67 & 0.67 & 0.67 & 0.67 & 0.68 & 0.68 & 0.68 & 0.68 & 0.68 & 0.69 & 0.69 & 0.69 & 0.69 & 0.69 & 0.70 & 0.70 & 0.70 & 0.70 & 0.70 & 0.71 & 0.71 & 0.71 & 0.71 & 0.71 & 0.72 & 0.72 & 0.72 & \\
\hline 4 & American Airlines & 0.65 & 0.65 & 0.65 & 0.66 & 0.66 & 0.66 & 0.66 & 0.67 & 0.67 & 0.67 & 0.67 & 0.67 & 0.68 & 0.68 & 0.68 & 0.68 & 0.68 & 0.69 & 0.69 & 0.69 & 0.69 & 0.70 & 0.70 & 0.70 & 0.70 & 0.70 & 0.71 & \\
\hline 5 & Lufthansa & 0.73 & 0.73 & 0.73 & 0.74 & 0.74 & 0.74 & 0.74 & 0.74 & 0.74 & 0.75 & 0.75 & 0.75 & 0.75 & 0.75 & 0.76 & 0.76 & 0.76 & 0.76 & 0.76 & 0.76 & 0.77 & 0.77 & 0.77 & 0.77 & 0.77 & 0.77 & 0.77 & 0.78 \\
\hline 6 & US airways & & & 0.57 & 0.57 & 0.58 & 0.58 & 0.58 & 0.58 & 0.59 & 0.59 & 0.59 & 0.59 & 0.60 & 0.60 & 0.60 & 0.60 & 0.61 & 0.61 & 0.61 & 0.61 & 0.61 & 0.62 & 0.62 & 0.62 & 0.62 & 0.63 & 0.63 & \\
\hline 7 & Air France & 0.68 & 0.68 & 0.68 & 0.69 & 0.69 & 0.69 & 0.69 & 0.69 & 0.70 & 0.70 & 0.70 & 0.70 & 0.70 & 0.71 & 0.71 & 0.71 & 0.71 & 0.71 & & & & & & & & & & \\
\hline 8 & Easyjet & & & & & & & & & & & & & & & & & & 0.82 & 0.82 & 0.82 & & & & 0.82 & 0.82 & 0.83 & 0.83 & 0.83 \\
\hline 9 & All Nippon & & & & & & & & & & & & & & & & & 0.73 & 0.73 & 0.73 & 0.73 & 0.74 & 0.74 & 0.74 & 0.74 & 0.74 & 0.74 & 0.75 & 0.75 \\
\hline 10 & Turkish Airlines & & & & & & & & 0.60 & 0.61 & 0.61 & 0.61 & 0.61 & 0.62 & 0.62 & 0.62 & 0.62 & & & 0.63 & 0.63 & 0.64 & 0.64 & 0.64 & & & & 0.65 & 0.65 \\
\hline 11 & British Airways & 0.61 & 0.61 & 0.61 & 0.62 & 0.62 & 0.62 & 0.62 & 0.63 & 0.63 & 0.63 & 0.63 & 0.64 & 0.64 & 0.64 & 0.64 & 0.65 & 0.65 & 0.65 & 0.65 & 0.65 & 0.66 & 0.66 & 0.66 & 0.66 & 0.67 & 0.67 & 0.67 & \\
\hline 12 & JetBlue Airways & & & & & & & & & & & & & & & & & & & & 0.97 & 0.97 & 0.97 & 0.97 & 0.97 & 0.97 & 0.97 & 0.97 & \\
\hline 13 & SAS & 0.61 & 0.62 & 0.62 & 0.62 & 0.62 & 0.63 & 0.63 & 0.63 & 0.63 & 0.64 & 0.64 & 0.64 & 0.64 & 0.64 & 0.65 & 0.65 & 0.65 & 0.65 & 0.66 & 0.66 & 0.66 & 0.66 & 0.66 & 0.67 & 0.67 & 0.67 & 0.67 & 0.68 \\
\hline 14 & KLM & 0.80 & 0.80 & 0.80 & 0.80 & 0.80 & 0.80 & 0.81 & 0.81 & & & & 0.81 & 0.81 & 0.82 & 0.82 & 0.82 & 0.82 & 0.82 & 0.82 & 0.82 & 0.82 & 0.83 & & & & & & \\
\hline 15 & Air Canada & 0.66 & 0.66 & 0.67 & 0.67 & 0.67 & 0.67 & 0.68 & 0.68 & 0.68 & 0.68 & 0.68 & 0.69 & 0.69 & 0.69 & 0.69 & 0.69 & 0.70 & 0.70 & 0.70 & 0.70 & 0.70 & 0.71 & 0.71 & 0.71 & & & 0.72 & 0.72 \\
\hline 16 & Alitalia & 0.70 & 0.71 & 0.71 & 0.71 & 0.71 & 0.71 & & & 0.72 & 0.72 & 0.72 & 0.73 & 0.73 & 0.73 & & & & & & & & & & & & & & \\
\hline 17 & Saudia & 0.41 & 0.41 & & & & 0.42 & 0.42 & 0.43 & 0.43 & & & & & & & & & & & & & & & & & & & \\
\hline 18 & Japan Airlines & 0.71 & 0.71 & 0.71 & 0.71 & 0.71 & 0.72 & 0.72 & 0.72 & 0.72 & 0.72 & 0.73 & 0.73 & 0.73 & 0.73 & 0.73 & 0.74 & 0.74 & 0.74 & 0.74 & 0.74 & 0.74 & & & & & & & \\
\hline 19 & Korean Airlines & & & 0.76 & 0.76 & 0.76 & 0.76 & 0.76 & 0.77 & 0.77 & 0.77 & 0.77 & 0.77 & 0.77 & 0.78 & 0.78 & 0.78 & 0.78 & 0.78 & 0.78 & 0.78 & 0.79 & 0.79 & 0.79 & 0.79 & 0.79 & 0.79 & 0.80 & 0.80 \\
\hline 20 & Qantas & 0.65 & 0.66 & 0.66 & 0.66 & 0.66 & 0.66 & 0.67 & 0.67 & 0.67 & 0.67 & 0.67 & & & & & & & & & & & & & & & & & \\
\hline 21 & Cathay & & & & & 0.005 & 0.65 & 0.65 & 0.65 & 0.66 & 0.66 & 0.66 & 0.66 & 0.66 & 0.67 & 0.67 & 0.67 & 0.67 & 0.67 & 0.68 & 0.68 & 0.68 & 0.68 & 0.69 & 0.69 & 0.69 & 0.69 & & \\
\hline 22 & Thai & & & 0.59 & 0.59 & 0.59 & 0.60 & 0.60 & 0.60 & 0.60 & 0.61 & 0.61 & 0.61 & 0.61 & 0.62 & 0.62 & 0.62 & 0.62 & 0.63 & 0.63 & 0.63 & 0.63 & 0.64 & 0.64 & 0.64 & 0.64 & 0.64 & 0.65 & 0.65 \\
\hline 23 & Alaska Airlines & & & & & & & 0.82 & 0.82 & 0.82 & 0.82 & 0.82 & 0.83 & 0.83 & 0.83 & 0.83 & 0.83 & 0.83 & 0.83 & 0.83 & 0.84 & 0.84 & 0.84 & 0.84 & 0.84 & 0.84 & 0.84 & 0.84 & \\
\hline 24 & GARUDA & & & & & & 0.31 & 0.32 & 0.32 & 0.32 & 0.33 & 0.33 & & & & & & & & & & & & & & & & & \\
\hline 25 & SIA & & & 0.78 & 0.78 & 0.78 & 0.79 & 0.79 & 0.79 & 0.79 & 0.79 & 0.79 & 0.79 & 0.80 & 0.80 & 0.80 & 0.80 & 0.80 & 0.80 & 0.80 & 0.81 & 0.81 & 0.81 & 0.81 & 0.81 & 0.81 & 0.81 & 0.82 & 0.82 \\
\hline 26 & Jet Airways & & & & & & & & & & & & & & & & & 0.36 & 0.36 & 0.36 & 0.37 & 0.37 & 0.37 & 0.38 & 0.38 & 0.38 & 0.39 & & \\
\hline 27 & Swiss & & & & & & & & & & & & & & & & & & & & 0.75 & 0.76 & 0.76 & 0.76 & 0.76 & 0.76 & 0.76 & 0.77 & 0.77 \\
\hline 28 & ASIANA & & & & & & & & & & & & 0.93 & 0.93 & 0.93 & 0.93 & 0.93 & 0.93 & 0.93 & 0.93 & 0.93 & 0.93 & 0.94 & 0.94 & & & & & \\
\hline 29 & Iberia & 0.70 & 0.71 & 0.71 & 0.71 & 0.71 & 0.71 & 0.72 & 0.72 & 0.72 & 0.72 & 0.72 & 0.73 & 0.73 & 0.73 & 0.73 & 0.73 & 0.73 & 0.74 & 0.74 & 0.74 & 0.74 & 0.74 & 0.75 & 0.75 & 0.75 & 0.75 & 0.75 & 0.75 \\
\hline 30 & Northwest & & & 0.73 & 0.73 & 0.73 & 0.73 & 0.74 & 0.74 & 0.74 & 0.74 & 0.74 & 0.74 & 0.75 & 0.75 & 0.75 & 0.75 & 0.75 & 0.75 & 0.76 & 0.76 & 0.76 & 0.76 & 0.76 & 0.76 & 0.77 & 0.77 & 0.77 & \\
\hline 31 & Continental & & 0.75 & 0.75 & 0.75 & 0.75 & 0.76 & 0.76 & 0.76 & 0.76 & 0.76 & 0.76 & 0.77 & 0.77 & 0.77 & 0.77 & 0.77 & 0.77 & 0.78 & 0.78 & 0.78 & 0.78 & 0.78 & 0.78 & 0.79 & 0.79 & 0.79 & 0.79 & \\
\hline 32 & TWA & 0.76 & 0.76 & 0.76 & 0.76 & 0.76 & 0.76 & 0.77 & 0.77 & 0.77 & 0.77 & 0.77 & 0.77 & 0.78 & 0.78 & 0.78 & 0.78 & 0.78 & 0.78 & 0.79 & & & & & & & & & \\
\hline 33 & Japan Air System & & & & & & & & 0.61 & 0.62 & 0.62 & 0.62 & 0.62 & 0.63 & 0.63 & 0.63 & 0.63 & 0.64 & 0.64 & 0.64 & & & & & & & & & \\
\hline 34 & American West & & & & & & & & & & & & & & & & & 0.87 & 0.87 & 0.87 & 0.88 & 0.88 & 0.88 & 0.88 & 0.88 & & & & \\
\hline 35 & Malaysian Airlines & & & & & & 0.57 & 0.57 & 0.58 & 0.58 & & 0.58 & 0.59 & 0.59 & 0.59 & 0.59 & 0.60 & 0.60 & 0.60 & 0.60 & 0.61 & 0.61 & 0.61 & 0.61 & 0.61 & 0.62 & 0.62 & 0.62 & 0.62 \\
\hline 36 & SwissAir & 0.85 & 0.85 & 0.85 & 0.85 & 0.86 & 0.86 & 0.86 & 0.86 & 0.86 & & & 0.86 & 0.86 & 0.87 & 0.87 & 0.87 & & & & & & & & & & & & \\
\hline 37 & Aeromexico & 0.57 & 0.57 & 0.57 & 0.57 & & & & & & & & & & 0.60 & 0.60 & 0.60 & 0.61 & 0.61 & 0.61 & 0.61 & 0.62 & 0.62 & 0.62 & 0.62 & 0.63 & 0.63 & 0.63 & 0.63 \\
\hline 38 & Mexicana & & & & & & 0.55 & 0.56 & 0.56 & 0.56 & 0.56 & 0.57 & 0.57 & 0.57 & 0.57 & & & & & & & 0.59 & 0.59 & 0.60 & & & & & \\
\hline 39 & Finnair & & & & & & & 0.98 & 0.98 & 0.98 & 0.98 & 0.98 & 0.98 & 0.98 & 0.99 & 0.99 & 0.99 & 0.99 & 0.99 & 0.99 & & & & & & & & & \\
\hline 40 & Iran & & & & & & & & & & & & & & & & & & & & & & 0.84 & 0.84 & 0.84 & 0.84 & 0.84 & 0.84 & \\
\hline 41 & Aerlingus & 0.73 & 0.73 & 0.73 & 0.73 & 0.73 & 0.74 & & & & & & & & & & & & & & & & & & & & & & \\
\hline 42 & First Choice & & & & & & & & & & & & & 0.89 & 0.89 & 0.89 & 0.89 & 0.89 & 0.89 & 0.90 & 0.90 & 0.90 & 0.90 & 0.90 & 0.90 & & & & \\
\hline 43 & Eastern & 0.65 & 0.65 & 0.65 & 0.65 & 0.66 & 0.66 & 0.66 & & & & & & & & & & & & & & & & & & & & & \\
\hline 44 & Pan American & 0.80 & 0.80 & 0.80 & 0.81 & 0.81 & 0.81 & 0.81 & 0.81 & & & & & & & & & & & & & & & & & & & & \\
\hline 45 & PIA & & & & & 0.42 & 0.43 & 0.43 & 0.43 & 0.43 & 0.44 & 0.44 & 0.44 & 0.45 & 0.45 & 0.45 & 0.45 & 0.46 & 0.46 & 0.46 & 0.47 & 0.47 & 0.47 & 0.47 & 0.48 & 0.48 & 0.48 & 0.49 & \\
\hline 46 & Hawaian & & & & & & 0.98 & 0.98 & 0.98 & 0.98 & 0.98 & 0.98 & 0.98 & 0.98 & 0.98 & 0.98 & 0.98 & 0.98 & 0.98 & 0.98 & 0.98 & 0.98 & 0.98 & 0.98 & 0.98 & 0.98 & 0.98 & 0.98 & \\
\hline 47 & Air new zealand & 0.74 & 0.74 & & & 0.75 & 0.75 & 0.75 & & & & & & & & & & & & & & & & & & & & & \\
\hline 48 & AVIANCA & 0.45 & 0.46 & 0.46 & 0.46 & 0.47 & 0.47 & 0.47 & 0.47 & 0.48 & 0.48 & & & 0.49 & 0.49 & 0.49 & 0.50 & 0.50 & 0.50 & 0.50 & 0.51 & 0.51 & & & & & 0.52 & 0.53 & \\
\hline
\end{tabular}




\section{Please cite as:}

Scotti, D., Volta, N. (2017). Profitability Change in the Global Airline Industry.

Transportation Research Part E, 102, 1-12.

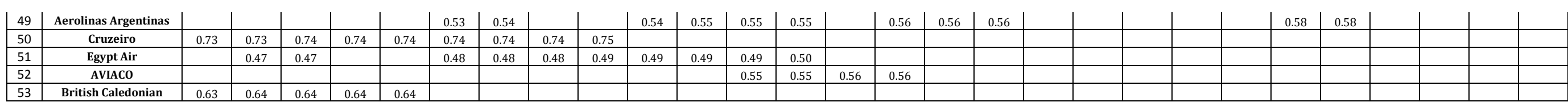


2017-03-31

\title{
Profitability change in the global airline industry
}

\author{
Scotti, Davide
}

Elsevier

Davide Scotti, Nicola Volta, Profitability change in the global airline industry, Transportation Research Part E: Logistics and Transportation Review, Volume 102, June 2017, Pages 1-12 https://doi.org/10.1016/j.tre.2017.03.009

Downloaded from Cranfield Library Services E-Repository 